\title{
BREEDING NEW CASTOR BEANS
}

\author{
Castor Oil Now Becoming of Immense Commercial Importance as Motor Lubri- \\ cant-Careful Breeding of Varieties Having Desired Attributes \\ Necessary to Produce Best Commercial Seed-Many \\ Characters Show Mendelian Behavior.
}

\author{
Orland E. White \\ Curator of Plant Breeding, Brooklyn Botanic Garden, Brooklyn, N. Y.
}

$\mathrm{T}$

HE well-known castor oil is expressed from the seeds of a Euphorbiaceous ornmental plant (Ricinus communis), related to our scarlet poinsettias. Hundreds of distinct varieties of this plant are known in the tropics-especially in India, where the bulk of the world's crop is grown. Most treatises roughly divide these numerous varieties into large and small-seeded types, the former producing supposedly less oil and of inferior quality. A collection of several hundred types (see Figs. 1 and 2), commercial and otherwise, assembled from various tropical and sub-tropical regions, discloses the fact that no sharp line can be drawn between the large Zanzibar types, running 450 to 600 beans per pound, and the small Bombay beans, running anywhere from 1.500 to 4,500 beans per pound, depending on the variety. All degrees of intergrades in size of beans exist, these, no doubt, resulting from more or less chance crossing, which wind and insects have brought about during the centuries of its cultivation.

BEANS MAINLY MMPORTED FROM INDIA

Of the million or more bushels of beans annually imported into this country through the port of New York, the bulk come from Madras and Bombay; a few from Mexico, Brazil, Argentine Republic. Java, and China. The Indian beans as they reach our factories are generally a mixture of such small and medium seeded types as are represented in Fig. 2. The large seeded types, shown in the same figure, were said to be Chinese and are grown considerably in Mexico. The oil content of the Indian beans runs as high as 55 per cent, while the large Zanzibar beans give only 35 per cent oil, and of inferior quality because of the increased amount of "acid." Shortly after the Civil War, castor oil bean farming in the United States became a promising local industry in Kansas, Illinois, and other Middle Western States, but overproduction and competition with cheap Hindu labor soon made it unprofitable. Castor oil beans, as late as twelve years ago, were raised commercially in Oklahoma, and the scarcity of imported beans and the increased demand for the oil, due to the war, will probably bring large areas in these sections again into castor oil bean cultivation. I Large sancly areas in the Gulf States, now largely waste land, are said to be eminently fitted for this crop. The crop runs anywhere from 10 to 40 bushels per acre, clepending largely on the variety planted, the soil, the climate, and the length of frostless season. Even as far north as Iowa, from 15 to 25 bushels per acre have been obtained.

The oil has innumerable uses, chief among these being its value in dyeing cloth, in medicine, and as an aeroplane motor lubricant. Its non-drying, nongumming properties, and its high density are said to make it especially desirable for lubricating the newly invented Liberty" motor. Normally this country uses about $1,000,000$ gallons annually, but the war and the increased use of aeroplanes after the war probably will many times increase this amount.

\section{BREEDING OF GOOD TYPES ESSENTIAL}

To make commercial castor oil bean growing in this country a permanent industry, requires the breeding of varie- 

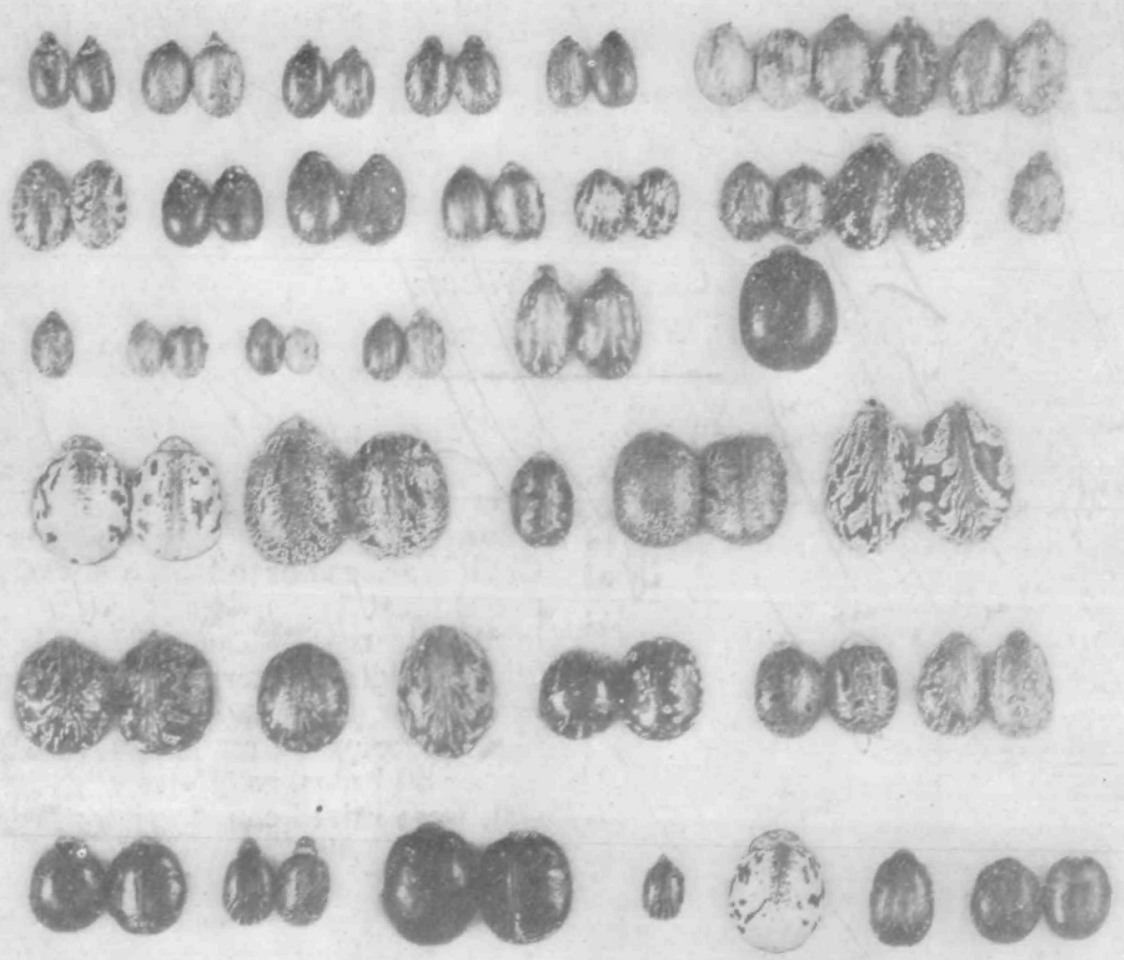

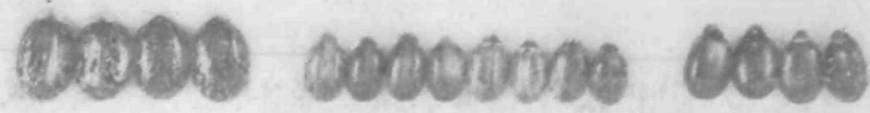
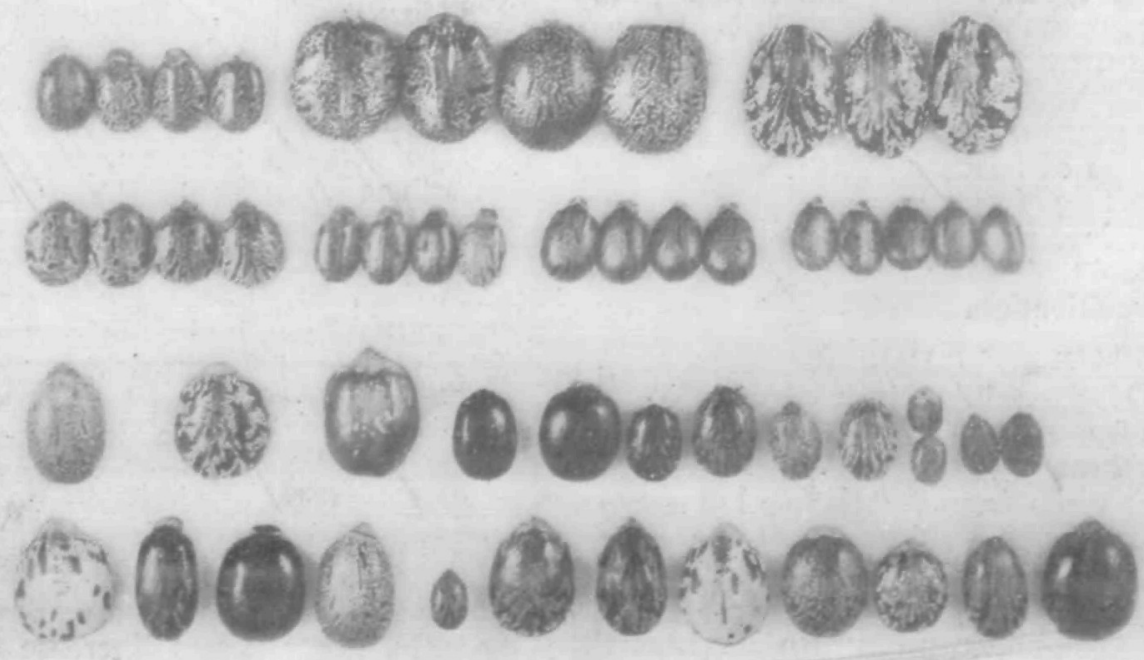

\section{VARIATION IN SIZE, SHAPE, PATTERN, AND COLORING}

Each group in all but the last two rows represents a distinct kind or variety. Often the beans are arranged to show upper and lower surfaces. The very large beans are Zanzibar types with low oil content. In the last two rows, each variety is represented usually by a

- . single bean. These beans are types from Mexico, Italy, Java, Zanzibar, Uganda and Rhodesia. (Reduced one-third.) (Fig. 1.) 


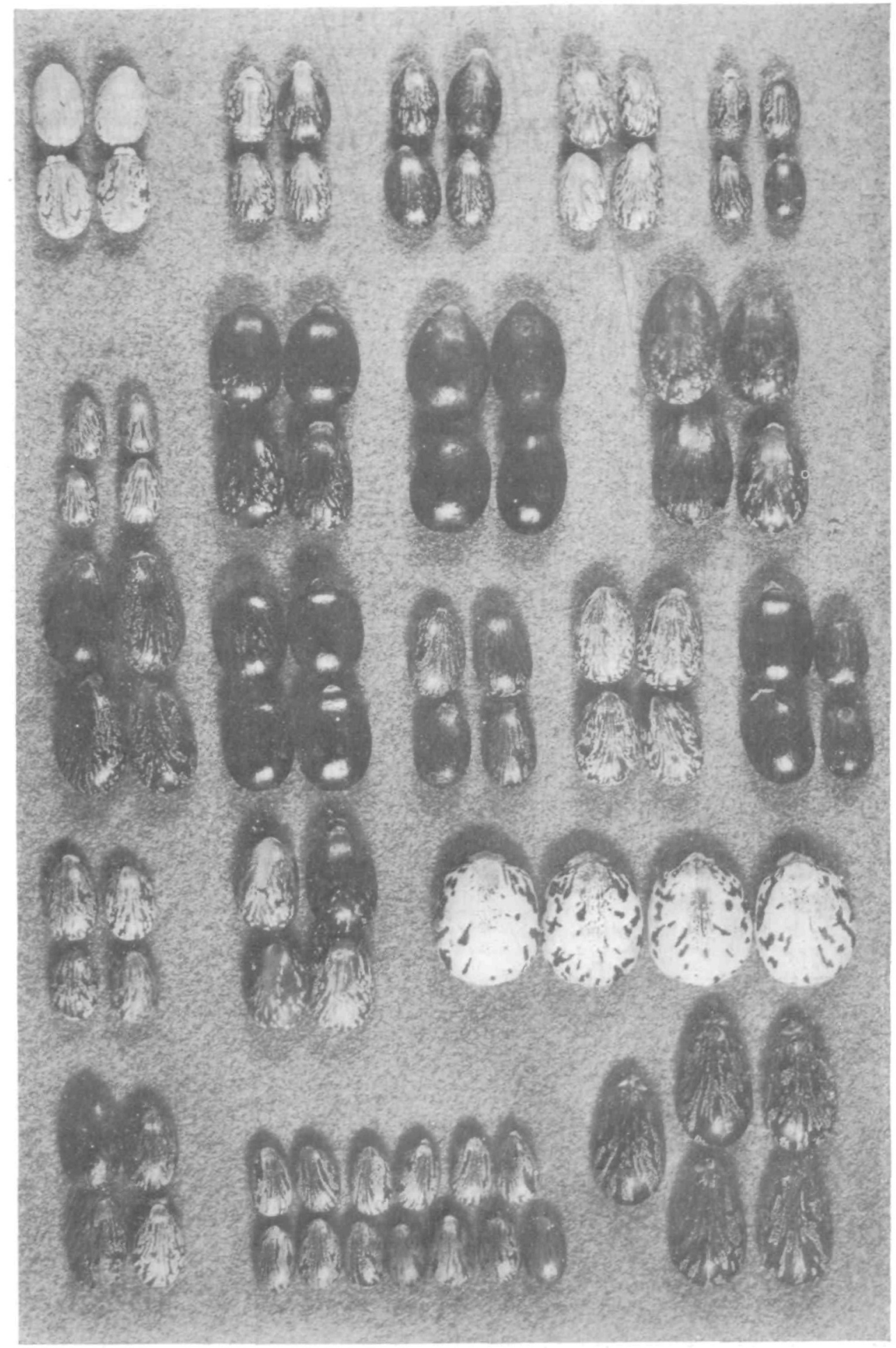

\section{COMMERCAL TYPES OF CASTOR BEANS}

Each of the groups represents one type. The first three rows represent corrmercal types of India. The last two rows are types from Mexico, Java, British West Indies and India. (Natural size.) (Fig. 2) 
ties with the highest possible oil content, the smallest amount of the objectionable "acid;" varieties adapted to such waste lands as those of the sandy areas of the Gulf Coast and other sandy regions of the southern United States, and, perhaps, the sandhills of $\mathrm{Ne}$ braska; varieties having close, compact, fruiting spikes with thin-walled, spineless, "non-popping" seed capsules. The plants should be prolific in fruiting spikes, early maturing, and bear over a long season. The materials for producing such varietal types already exist among the innumerable forms of castor beans, the man problem being to bring them together into one or more commercial varieties.

So tar as the writer knows, no very serious attempt has been made to do this, although some plant-breeding work and varjety testing has been done in Algeria, British West Indies, Egypt, and India. From several years experience, the writer has found the castor oil plant an excellent subject for plantbreeding work. The plants are easily grown, comparatively free from disease, the seeds remain viable for severai years with a very high per cent of germination. All the types, even to the most extreme, readily cross, giving rertile $F_{1}$ and $F_{2}$ hybrids. Some varieties when crossed, give a much larger yield of seed in the $F_{1}$ generation, while of other types. as in maize, this is not true. Among the characters showing Mendelian behavior are stem, foliage, and seed coat color, glaucous or non-glaucous plants, "popping" or "non-popping" seed capsules (dehiscent or indehiscent), types of seedcoat mottling. seed size and shape, height of plant, compactness and size of fruiting spike, time of maturity, certain leaf characters, etc. Only a few of these characters have been studied in enough detail so that they may be placed on a factorial basis. Such a character as indehiscent capsules, when combined with thin capsular walls and other characters should be especially valuable in a variety grown for oil, since a large per cent of the seeds are not wasted by the popping of the mature capsules. Also labor is saved. since it is not necessary to har- vest the crop once or twice a week in order to avoid loss, as is the case with common popping varieties. This characteristic is easily transferred as ip)parently not more than two pair of factors are involved.

\section{PLANT IS MONOECIOUS}

As is well known, the castor bean plant is monoecious, the male and female flowers appearing on different portions of the same flcwering spike (see Frontispiece). Both types of flowers mature at about the same time, the male flowers perhaps slightly earlier. All the flowers, either male or female, of the same spike, do not mature at the same time. The proportion of female flowers destined to produce mature capsules, usually involve a week or so in setting so that the seeds of one spike ripen at about the same time. Square bottomed, light colored manila paper bags are used to cover the inflorescence when selfed seed is desired or when crosses are made. The sacks should be of fair size, as it may be desirable to keep the rapidly lengthening inflorescence covered for a considerable period, until all danger of "adventitious" female flowers appearing and contamination resulting thereby, lias been eliminated. After bagging, when selfed seed is desired. the bags should be shaken every few days as the pollen matures, so as to insure plenty of "fruit" setting. In a windy country this may not be neces. sary, but the writer finds it to be so in his work in Brooklyn.

\section{GENTERALLY BREED TRUT:}

Observations based on cultures in the breeding plots at the Brooklyn Botanic Carden show that many of the varieties, much to my surprise (since the castor oil plant is monoecious and windpollinated), breed true to many of their most prominent characters inmediately. Data from progeny of plants of different varieties, grown close together, indicate that very little cross-fertilization took place (probably not more than $5 \%$ ). even when conditions appeared most favorable. This may be accounted for, perhaps, by the copious supply of pol- 


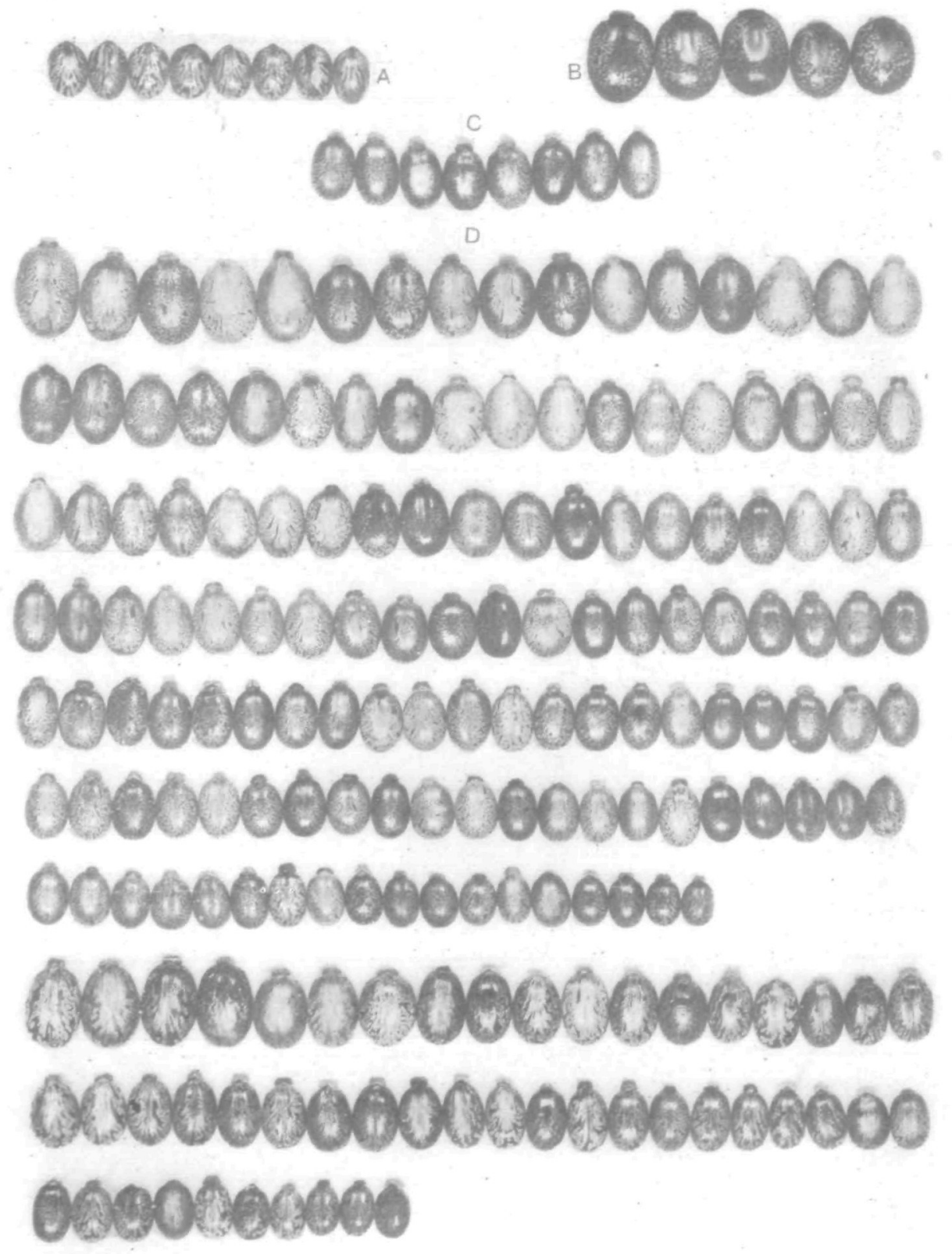

RESULTS FROM CROSSING DIFFEREYT TYPES

Illustrates inheritance of seed dimension and coarse and fine seedcoat mottling. A. Maternal parent. B. Seeds in all respects similar to paternal parent. C. $F_{1}$, progeny. Note the uniform appearance both as to size and mottling the $F_{1}$, progeny seeds. $D . F_{2}$, in progeny. The coarse and fine mottled segregates are arranged in a separate series. In every case, each single bean represents a typical bean from one plant. (Reduced one-third.) (Fig. 3.) 


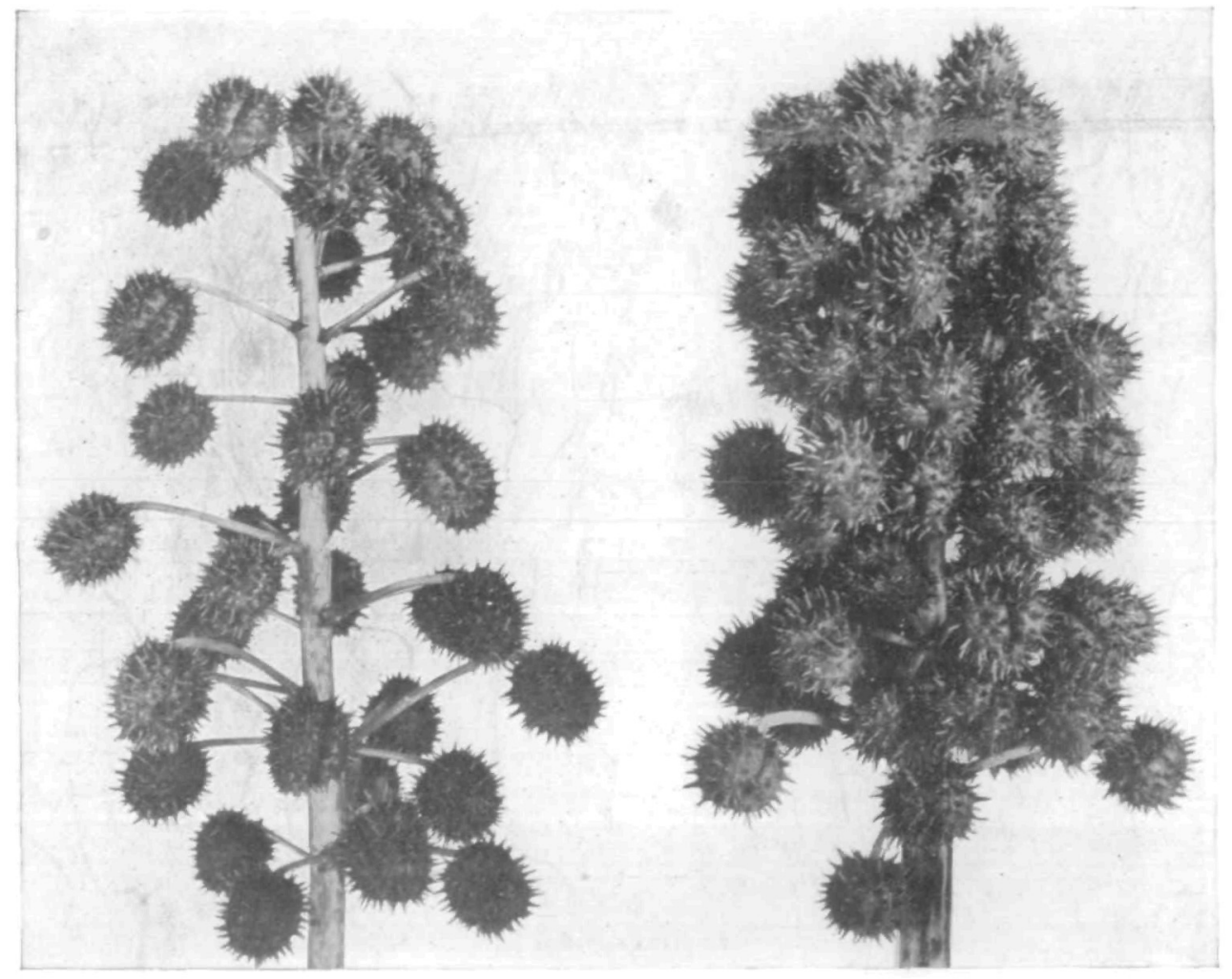

\section{LOOSE AND COMPACT FRUITING SPIKES}

The types with compact spikes in general are greater seed producers, and hence of more commercial value. (Fig. 4.)

len of the male flowers, the comparative proximity of the female flowers, and the sheltering effect of the foliage against air currents bearing foreign pollen. 'The flowers are said to be excellent honey producers for bees, so where these are common one might expect a much greater amount of cross fcrtilization.

In selection work, such as the isolation of high oil producing types, it secms best and most practical to insure complete isolation by using paper bags as mentioned above. In making crosses, the male flowers may be easily removed without harming the spike and the remaining female flowers. Ma!e flowers usually mature and shed their pollen in early morning. 'The pollen remains viable for at least a week, when kept in a dry place.

\section{Breeding Sows Before Litters are Weaned}

Experiments described in the monthly Bulletin of the Ohio Agricultural Experiment Station for May. 1918, woul.1 indicate that there is no danger in breeding sows when their litters are from 43 to 56 days of age. Conception seems to take place just as readily, the milk flow is apparently not affected and the pigs seem to thrive just as well as if hreeding did not take place until the litter was weaned. 